\title{
Reforma psiquiátrica: integrando experiências brasileiras e espanholas no coidado integral e territorializado em saúde mental
}

\author{
Magda Dimenstein \\ Universidade Federal do Rio Grande do Norte
}

E ste dossiê reúne atores do campo da saúde mental espalhados em diversos países, contemplando trabalhadores, usuários, docentes e pesquisadores, os quais se disponibilizaram a contribuir com esta publicação, seja apresentando suas experiências ligadas ao cotidiano dos serviços de atenção psicossocial, seja na forma de avaliadores convidados, agregando novas perspectivas à discussão dos rumos do processo de Reforma Psiquiátrica. Gostaria de agradecer à imensa generosidade de todos pela colaboração.

Por ocasião do Estágio Pós-Doutoral realizado na Espanha entre agosto de 2009 e julho de 2010 foi possível conhecer algumas experiências e práticas no campo da atenção e reabilitação psicossocial que trazem contribuições valiosas ao cenário atual brasileiro, momento que se comemora 10 anos de aprovação da Lei 10.216/01 e os inegáveis avanços em termos da consolidação da rede substitutiva, não hospitalocêntrica e manicomial. Contudo, simultaneamente, enfrentamos o desafio de fazer ajustes e qualificar aquilo que vem sendo conquistado nesses 30 anos de luta para garantir a sustentabilidade de um processo que visa, acima de tudo, a desconstrução definitiva das estruturas asilares e segregadoras, a garantia de acesso a uma rede integral de saúde e a participação ativa de todos os atores na formulação e implantação da política de saúde mental no país. Nesse sentido, os trabalhos aqui apresentados favorecem a reflexão acerca de alguns aspectos desse processo que precisamos nos debruçar seriamente daqui para frente, pois são pontos que ainda estamos tentando encontrar saídas, formular propostas, reavaliar modelos em curso, a saber:

1. Diagnóstico precoce e tratamento de transtornos mentais na atenção primária.

2. Estratégias de intervenção à crise, redução de danos, serviços de urgência e hospitalização breve.

3. Experiências diversificadas de dispositivos residenciais e atenção domiciliar.

4. Suporte às famílias e autogestão dos cuidados.

5. Ações intersetoriais de reabilitação e inclusão social (geração de renda e garantia de direitos).

6. Continuidade de cuidados e estratégias multimodais (boas práticas) integrando diferentes dispositivos de cuidado.
A Espanha foi eleita como lócus de realização do estágio pós-doutoral porque apesar de ter iniciado a reforma psiquiátrica tardiamente em comparação a outros países europeus, desde o processo de redemocratização do país a partir de meados de 1970, vem apresentando-se como uma referência no cenário internacional por ter conseguido formular uma política pública inovadora, social e tecnicamente avançada (Desviat, 1999) ${ }^{1}$. Isso significa um atrelamento a um processo mais amplo de reforma sanitária e de garantia de direitos e cidadania muito similar ao que vem ocorrendo no Brasil.

De sua história, de seus acertos e erros, construíram os pilares de uma rede de saúde mental de base comunitária e participativa, cujos recursos de atenção sanitária e social vêm ampliando-se progressivamente ao largo desses anos. Para tanto, partiram de objetivos muito bem definidos: fechamento do hospital e a criação de uma rede de recursos com um amplo leque de programas interdependentes que garantisse assistência e suporte social a toda a população do território. Para pôr em funcionamento tal plano algumas cidades espanholas adotaram uma série de medidas. Ressaltamos aqui o redirecionamento dos fluxos na rede, posicionando a atenção primária como porta de entrada e regulador do sistema; a redefinição da atenção especializada; criação de unidades de retaguarda à crise e atenção às emergências e, principalmente, $\mathrm{o}$ investimento em programas de reabilitação e apoio comunitário contemplando a questão da moradia e do trabalho (Desviat, 2007) ${ }^{2}$. Essas iniciativas vêm produzindo impactos importantes, não só entre ex-usuários do hospital, mas em toda a comunidade, e em particular, nas famílias de portadores de transtornos mentais.

Entretanto, tal processo, especialmente na comunidade de Madrid, vem sofrendo um retrocesso em função do acirramento das políticas neoliberais com ênfase na privatização do sistema sanitário e no desmantelamento da rede de atenção psicossocial construída em mais de 25 anos de luta democrática no país. Durante a realização da "Jornada sobre modelos y estratégias en salud mental" 3 ocorrida em Madrid no final de 2008, houve consenso entre os participantes em termos da "pérdida del papel de lo público y cómo los grupos que manejan el presupuesto ponen en peligro el modelo volviendo a modelos neo-institucionalizadores".

Ademais, que existem diferenças tanto no ritmo quanto 
no grau de desenvolvimento do modelo comunitário no país; há riscos de uma super especialização na atenção em saúde mental ficando encapsulada dentro de uma rede já fragmentada, assim como o aumento da participação do setor privado com diminuição do volume investido em saúde mental, contratação de pessoal e ausência de transparência em termos dos gastos. Ou seja, "el objetivo final es convertir la sanidad en un mercado rentable para intereses particulares"

O diagnóstico da situação em Madrid também é preocupante, cujo panorama põe em risco a sustentabilidade do modelo comunitário. Dentre os problemas identificados por esse coletivo estão: a atenção primária está estrangulada financeiramente; o peso do hospital privado e das empresas sanitárias está avançando; o conceito de território vem perdendo sua força e função de ordenadora de rede frente ao novo marco de competência livre dos hospitais; além das dificuldades em dar seguimento a diversos programas em saúde mental como o de Continuidade de Cuidados.

No Brasil, vivemos tempos de contrarreforma também. Não é preciso ir muito longe para reconhecermos que por trás dos discursos atuais de certos setores da sociedade aparentemente comprometidos com a mudança no modelo assistencial em saúde mental, há um nítido interesse na manutenção das formas asilares de tratamento e de todo o aparato teórico-prático calcado em uma racionalidade científica que tem como eixos de sustentação a concepção de doença mental, a autoridade e o poder psiquiátricos, o enclausuramento e a contenção. Esse movimento de contrarreforma sempre existiu no país, mas vem ganhando adeptos nos últimos anos pelo seu poder de articular forças alinhadas ao conservadorismo, aos interesses econômicos dos empresários donos de hospitais e interesses corporativos dos profissionais. Esse fato, entretanto, deve servir de alerta a todos nós envolvidos na luta antimanicomial de não esquecermos da necessidade de avaliação e invenção permanente das propostas de reforma psiquiátrica, da política nacional de saúde mental, no sentido de mantermos sua potência de ruptura com as ideologias do medo, da exclusão e da intolerância tão avassaladoras nos últimos tempos. Consideramos que o conhecimento e análise dessas experiências espanholas podem ampliar as perspectivas de sustentabilidade do nosso processo local.

A primeira delas é uma análise feita por Manuel Desviat acerca da situação da reforma psiquiátrica depois de três décadas de desenvolvimento na Espanha, seus êxitos e fracassos. O autor discute o grau de implantação do modelo de saúde comunitária, bem como as insuficiências assistenciais, normativas e formativas. Por outro lado, analisa as conquistas tais como o desenvolvimento dos recursos alternativos e a perda da hegemonia do hospital psiquiátrico, assim como as ameaças ao processo advindas, principalmente, das mudanças produzidas na gestão dos serviços sociais e sanitários, da crescente privatização dos serviços, da precarização teórica e das mudanças na demanda da população usuária.

O segundo artigo trata do tema da Reabilitação Psicossocial, considerada um ingrediente chave na eficácia dos processos de desinstitucionalização, recuperação e inclusão social dos portadores de transtornos mentais. Em função disso, Mariano Hernandez Monsalve descreve as etapas pelas quais as propostas reabilitação psicossocial foram passando na Espanha a partir de 1986, data da promulgação da Lei Geral de Saúde, até discutir o cenário assistencial atual e as perspectivas de futuro nesse campo.

Na sequência somos contemplados com dois trabalhos da psiquiatra Ana González Rodriguéz focados na discussão dos Programas de Continuidade de Cuidados, eixo fundamental na condução das propostas de cuidado e reinserção dos portadores de transtornos mentais na Espanha, e por que não dizer, de articulador da rede. No primeiro deles, a autora faz uma revisão acerca da origem destes programas, seu desenvolvimento, assim como seus êxitos e fracassos. No segundo artigo, traz uma experiência em curso no Centro de Salud Mental de Chamartín em Madri para ilustrar o modo como operam com esse dispositivo e as formas de intervenção junto à população local. Acredito que o Programa de Cuidados Continuados/PCC e as correspondentes Equipes de Continuidade de Cuidados/ECC e de Apoio Social e Comunitário/EASC fornecem elementos importantes, pois são responsáveis pela elaboração e acompanhamento de um plano individualizado de intervenção ou Plano de Cuidados Continuados que envolve o acolhimento, avaliação, definição das estratégias de derivação para outros dispositivos de saúde mental e seguimento dos processos em curso, inclusive, definindo critérios para a lista de espera e alta. As equipes de Apoio Social e Comunitário são parceiras nesse processo e constituem uma estratégia de atenção domiciliar e social. Esse modelo, bastante distinto do que operamos aqui, pode nos ajudar a fazer ajustes na lógica que hoje organiza a proposta dos Projetos Terapêuticos Singulares e o matriciamento em Saúde Mental.

Outra experiência em destaque é o artigo de Alberto Fernández Liria, Ana Moreno Pérez, Juan González Cases, vinculados à rede de atenção em saúde mental do município de Alcalá de Henares e Torrejón de Ardoz, localizados na zona metropolitana de Madri. Os autores descrevem a estrutura e funcionamento dessa rede que integra 26 dispositivos e 229 trabalhadores, as fontes de financiamento e parceria com o setor privado, além das atividades de docência e investigação.

José Carmona Calvo e Francisco del Río Noriega apresentam nos dois artigos seguintes o processo de transformação dos recursos psiquiátricos na região da Andaluzia, sul da Espanha. O primeiro deles faz uma análise histórica do processo de reforma psiquiátrica na região, relata os movimentos por parte dos profissionais nos últimos anos da ditadura franquista e as mudanças advindas a partir da instauração da democracia, a qual permitiu o desenvolvimento de políticas sanitárias e a implantação de novos modelos de atenção em saúde mental. O segundo trata de como se deu o processo de integração da saúde mental ao sistema de saúde geral, o desmantelamento dos hospitais psiquiátricos e a rede assistencial e social construída para portadores de transtornos mentais na região. Finaliza com uma análise dos avanços e desafios postos na atualidade.

"El programa de atención psiquiátrica dirigido a enfermos mentales sin hogar" é uma experiência inovadora em Madri que vem sendo conduzida desde 2003 pela psiquiatra Maria Isabel Vázquez Souza, responsável pelo oitavo artigo desse dossiê. Aqui são apresentados os objetivos do programa: atender moradores de rua portadores de transtornos mentais e 
servir de ponte para os serviços sanitários e sociais, os quais essa população não tem acesso. A autora faz uma descrição dos modelos teóricos que orientam a proposta (outreach, tratamiento comunitario asertivo y modelo de recuperación), bem como o cotidiano da equipe multidisciplinar, suas atividades, as dificuldades e barreiras para a operacionalização do trabalho junto a essa população de rua. Esse programa, apesar de distinto da proposta atual dos Consultórios de Rua, lida com usuarios de álcool e drogas, com pessoas vulneráveis à diversos tipos de violência, desvinculadas de redes de apoio social e familiar. Considero que a experiencia de trabalho dessa equipe com moradores de rua é extremamente desafiante, impõe limites concretos à atuação da equipe multiprofissional, requer uma série de habilidades do ponto de vista de coordenação e gestão do trabalho, assim como dificuldades técnicas e pessoais, pois exige dos profissionais uma visão ampliada, contextualizada e sensível acerca da problemática da rua, fortemente articulada à pobreza, à exclusão, à falta de acesso a recursos comunitários e sanitários.

A experiência na Espanha me pôs em contato com uma complexa rede de serviços sanitários e sociais que funcionam de forma dinâmica e coordenada em um determinado território, garantindo a integração dos serviços de tratamento, reabilitação e suporte social e, principalmente, evitando a fragmentação entre os diferentes serviços e a dispersão do usuário na rede, nos espaços comunitários, junto aos dispositivos de apoio social. Trata-se de um conjunto de ferramentas que vêm viabilizando mudanças consistentes na atenção em saúde mental, as quais se articulam em grandes eixos: redefinição da gestão dos dispositivos institucionais; a perspectiva de continuidade de cuidados; atenção primária como porta de entrada e regulador do sistema; criação de unidades de retaguarda à crise e atenção às emergências e, principalmente, o investimento em programas de reabilitação e apoio comunitário contemplando alternativas de moradia e trabalho. Este artigo de minha autoria visa apresentar estas estratégias e sua contribuição ao processo brasileiro de reforma psiquiátrica.

Os dois últimos artigos dizem respeito à experiências de usuários e equipes sintonizadas com a perspectiva do fortalecimento dos movimentos sociais e dispositivos associativos, do empoderamento e participação de usuários e familiares no processo de reinserção social. O artigo de Juan Carlos Casal recorre suas experiências pessoais e de coordenador da Associação Alonso Quijano desde 2002. O autor faz uma discussão sobre estigma e o isolamento dos portadores de transtornos mentais e apresenta a proposta da associação, seus participantes e atividades regulares, bem como os desafios enfrentados no sentido de dar sustentabilidade e vigor a mesma. Nessa mesma linha de trabalho, apresentamos o artigo da equipe profissional do Centro de Rehabilitación Psicosocial (CRPS) Los Cármenes que desenvolve desde 2004 um projeto que consiste na realização de um programa de radio comunitária chamada "Ábrete Camino". Os autores apresentam a metodologia de trabalho baseada na perspectiva da recuperação, a qual permite que os participantes sejam cada vez mais protagonistas, tanto no programa, quanto em suas vidas. $\mathrm{O}$ artigo é um relato dos próprios usuários que conduzem o programa semanal de rádio onde nos contam sua experiência através de um debate direto e franco.

Convidamos a todos para conhecer essas experiências, que apesar de se situarem em uma realidade bastante distinta da nossa, podem aportar contribuições preciosas ao que estamos produzindo no Brasil. Trata-se de inovações ou estratégias de luta que proliferam no campo da saúde mental frente às demandas cambiantes do próprio campo que nos exigem a reinvenção seja no âmbito das proposições, dos modelos e diretrizes da política pública, seja nos níveis moleculares das relações cotidianas, das práticas de cuidado, dos modos de sociabilidade e sensibilidade gestados nesses tempos onde os espaços de captura estão cada vez mais ampliados. 
1. Desviat, M. (1999). A Reforma Psiquiátrica. Rio de Janeiro: Fiocruz.

2. Desviat, M. (2007). De loucos a enfermos. De la psiquiatria del manicômio a la salud mental comunitária. Ayuntamiento de Leganés.

3. Jornada organizada conjuntamente pela AEN, FEARP e pela Plataforma por la Defensa de la Salud Mental Pública, em 30 de novembro de 2008, no Colegio Oficial de Médicos.

4. Mesa de Debate promovida pela AMRP intitulada La situación de la atención en Salud Mental en Madrid, 13 de fevereiro de 2008, Salón de Actos Hospital Niño Jesús

Magda Dimenstein

Endereço: Universidade Federal do Rio Grande do Norte

Centro de Ciências Humanas, Letras e Artes

Departamento de Psicologia

Campus Universitário s/n, Lagoa Nova

Natal/RN, Brasil. CEP: 59094-010

Telefone: 55(84) 3215-3590.

E-mail:mgdimenstein@gmail.com 